Instructions for authors, subscriptions and further details:

http://brac.hipatiapress.com

\title{
Abstracción Referencial. Philippe Decrauzat. Formas que Omiten a lo que Aluden
}

Ricardo Trigo 1

1) Universitat de Barcelona. España

Date of publication: October 3rd, 2015

Edition period: October 2015 - February 2016

To cite this article: Trigo, R. (2015). Abstracción referencial. Philippe Decrauzat. Formas que omiten a lo que aluden. Barcelona, Research, Art, Creation, 3(3), 205-232. doi: 10.17583/brac.2015.1573

To link this article: http://dx.doi.org/10.17583/brac.2015.1573

\section{PLEASE SCROLL DOWN FOR ARTICLE}

The terms and conditions of use, except where otherwise noted, are related to the Open Journal System and to Creative Commons Attribution License (CCBY). The indication must be expressly stated when necessary. 
BRAC - Barcelona Research Art Creation. Vol. 3 No. 3, October 2015, pp. 205-232

\section{Referential Abstraction. Philippe Decrauzat, Forms that Omit that which they Allude to}

Ricardo Trigo

University of Barcelona

(Received: 15 June 2015; Accepted: 21 July 2015; Published: 3 October 2015)

\section{Abstract}

In this text we will analyze the work of artist Philippe Decrauzat (Lausanne, 1974). His work will help us define a type of abstraction which shows formal similarities to iconic works of the tradition of abstract art, reminiscent of minimalist artists such as Robert Morris and Frank Stella, or op art pieces by Waclaw Szpakowski from the 1920s. Despite Philippe Decrauzat's use of certain codes and formal similarities, his objective is to make a conceptual twist on these. He does so by placing the viewer far from a traditional safe place forged during the twentieth century; the knowledge of abstract art's language.

Keywords: Philippe Decrauzat, minimalism, Post-painterly abstraction, op art, institutionalization, knowledge, repetition. 
BRAC - Barcelona Research Art Creation. Vol. 3 No. 3, October 2015, pp. 205-232

\section{Abstracción Referencial. Philippe Decrauzat. Formas que Omiten a lo que Aluden}

Ricardo Trigo

Universidad de Barcelona

(Recibido: 15 Junio 2015; Aceptado: 21 Julio 2015; Publicado: 3 Octubre 2015)

\section{Resumen}

En este texto vamos a analizar el trabajo del artista Philippe Decrauzat (Lausanne, 1974). Su obra nos servirá para definir un tipo de abstracción formalmente muy similar a trabajos icónicos de la tradición del arte abstracto, trabajos que nos pueden recordar a obras de artistas minimalistas como Robert Morris y Frank Stella, piezas op art, o trabajos de Waclaw Szpakowski de los años 1920. Sin embargo, su objetivo es el de realizar un giro conceptual sobre esas semejanzas y códigos, de colocar al espectador en lugares alejados de la red de seguridad que constituye el saber del lenguaje del arte abstracto forjado a lo largo del siglo XX.

Palabras clave: Philippe Decrauzat, minimalismo, abstracción pospictórica, op art, institucionalización, saber, repetición. 
amos a recorrer varias exposiciones del artista suizo Philippe Decrauzat, concretamente $O n$ the retina (2011), realizada en House of Art Ceské Budejovice en la República Checa, y Corps Flottants (2013) realizada en la galería Española Parra \& Romero de Madrid. A lo largo del texto, desgranaremos el trabajo de Decrauzat y estableceremos puntos de encuentro y desencuentro con movimientos artísticos de la década de 1960 como la abstracción postpictórica, el minimalismo y el op art, mediante la selección de distintos puntos de vista sobre cada uno de ellos. Con el objetivo de analizar la propuesta del artista y contextualizarla en un marco actual, ver como operan sus formas y que relación establece con la herencia del arte abstracto que evocan.

\section{Formas Extensivas}

La exposición On the retina (2011) está compuesta de tres espacios a través de los cuales se despliegan cuatro propuestas distintas. Las sala principal acoge las piezas Pinturas (2011) (Figuras 1 y 2), una segunda sala muestra tres dibujos en tinta sobre papel D.T.A.B.T.W.H.A.H.E (2010) (Figura 3) mientras que en la tercera sala podemos ver la película en $16 \mathrm{~mm}$ Screen-o-scope (2010) (Figura 4). Para finalizar, una quinta pieza Méthode d'objectivation critique, (dispersion) (2011) (Figuras 1, 2, 7 y 8) concluye la exposición, se trata de unos pequeños fragmentos en forma de círculos y de líneas orgánicas dispuestos por el suelo de la primera sala, inspirados en fragmentos de una silla de finales del siglo XIX y moldeados en hormigón. 


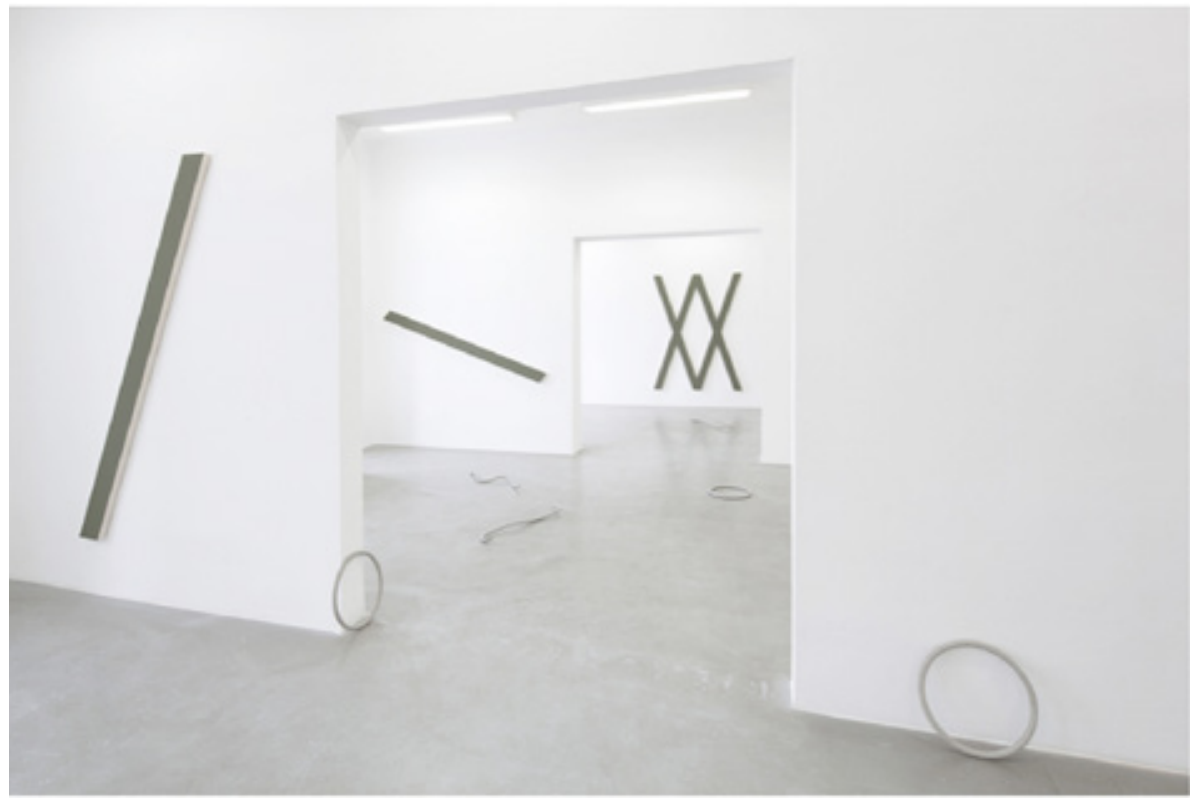

Figura 1. Philippe Decrauzat. Vistas de la exposición On the retina (2011). House of Art Ceské Budejovice, República Checa. Foto: Jan Mahr. Cortesía del artista y de la galería Parra \& Romero. (C)

El primer espacio (Figuras 1 y 2) acoge una serie de telas recortadas en forma de líneas diagonales, dispuestas individualmente y pintadas con acrílico, presentadas a modo de secuencia exponencial: primero una diagonal a la izquierda, luego otra a la derecha y seguidamente otra constituida con cuatro diagonales y formando una doble X y una W. En estas pinturas, la tela se ajusta a la forma representada shaped canvas, utilizando el mismo recurso formal que artistas pertenecientes a la abstracción pospictória de la primera mitad de los años 1960 en Estados Unidos. Carla Beatriz Franco Ruschmann (2003) definiendo la abstracción postpictória en su tesis doctoral Arte geométrico: Análisis y tendencias de su desarrollo plástico, comenta:

La obra geométrica de esta tendencia usualmente es realizada con pocos elementos, sencilla y pura en cuanto a formas y colores, con una lectura muy clara e inmediata. Como novedades técnicas aporta la adecuación del soporte a la forma expresada. (p.178) 
La semejanza de los principios formales de la abstracción postpictória con la serie de pinturas Pinturas, (2011) (Figuras 1 y 2) de Decrauzat es más que evidente. Sin embargo, Decrauzat siempre presenta sus pinturas junto a otros elementos, abriendo una nueva lectura, además de la referencia más obvia. Este principio tan definido acerca del posicionamiento de la abstracción postpictória, que también será compartido posteriormente dentro del minimalismo por algunos de sus integrantes como en el caso del norteamericano Frank Stella, es el que Amalia Martínez Muñoz (2001) analiza de la siguiente manera:

Durante la década de los sesenta, la búsqueda de una pureza pictórica exenta de toda espacialidad que pudiera provocar efectos de figura y fondo, le llevó a realizar una serie de cuadros negros surcados por líneas blancas [...]. Ese extremo reduccionismo de color y forma, era la fórmula con la que Stella quería afirmar el carácter objetual de sus pintura, eludiendo todo posible contraste de valor que pudiera derivar en un efecto ilusorio de profundidad. [...]. Al adecuar la forma de la superficie pictórica a las geometrías pintadas, se elimina toda diferencia entre la figura y su representación; los cuadros se presentan como una lograda síntesis entre la estructura interna y externa de la pintura. (p.78) 


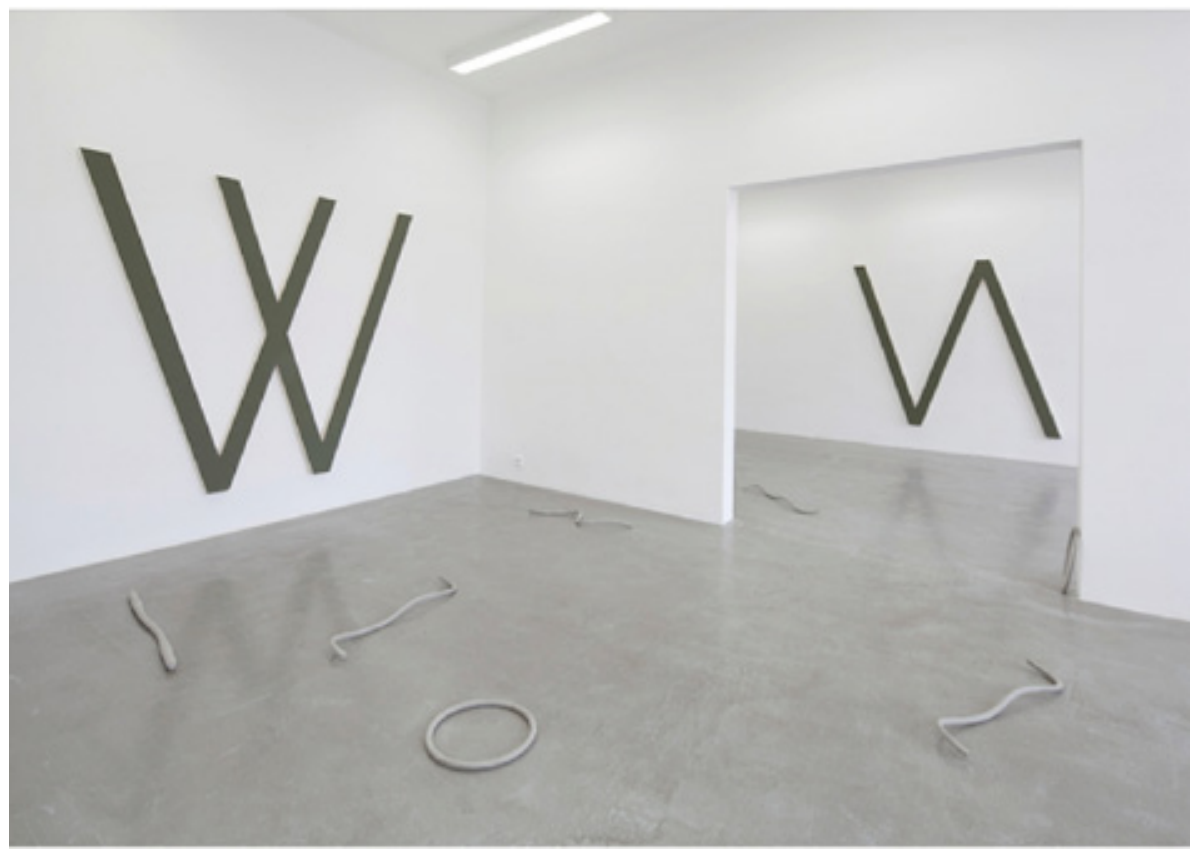

Figura 2. Philippe Decrauzat. Vistas de la exposición On the retina (2011). House of Art Ceské Budejovice, República Checa. Foto: Jan Mahr. Cortesía del artista y de la galería Parra \& Romero. (C)

Anna Maria Guasch (1997) explica los principios ideológicos de la abstracción postpictórica con el catálogo de la exposición Toward a New Abstraction (1963) realizada en el Jewish Museum de Nueva York, en la que participaron artistas como Frank Stella y Kenneth Noland, de la siguiente manera:

[...] habían propuesto un arte purista, liberado de los esquemas relacionales, basado en la simetría, en la repetición modular y en la ausencia de sistemas ilusionistas. Era, pues, el momento de la estética formalista, aquella que defendía que el arte visual debía limitarse a la experiencia visual, sin ninguna referencia a otras categorías de experiencia, aquella a la que sólo interesaban los problemas formalistas del arte y que anteponían a cualquier otro atributo pictórico o escultórico, el de la calidad. (p.153) 
En este caso Decrauzat, a pesar de resolver formalmente la serie de Pinturas (2011) (Figuras 1 y 2) de un modo muy similar a como lo hacía Stella en obras como Telluride, Creede I, Creede II (1961), tiene un objetivo muy distinto. El objetivo de Decrauzat, como veremos, es el desplegar las diagonales en otros contextos, como por ejemplo en la exposición Anisotropy (2011) (Figura 7), realizada por el artista también en el 2011 en Le Plateau/FRAC de París, donde emplea los mismos recursos gráficos [las diagonales negras] para presentarlos dispuestas sobre un mural de corte ilusionista, transgrediendo el principio de la abstracción postpictórica y como dilucidaremos, cualquier otro determinismo estilístico.

Con dos elementos geométricos simples, dos líneas en diagonal, ya sean pintadas sobre la pared o como en el caso que nos ocupa en la exposición $O n$ the retina (2011), sobre tela, Decrauzat realiza distintas combinatorias posibles entre ellas, presentándolas de forma individual o de forma acumulativa, como objeto o incorporadas en el espacio arquitectónico. Siempre mediante el mismo gesto, cruzándolas o superponiéndolas, el artista nos presenta un amalgama de formas posibles de cómo percibir diagonales, pasando de la contemplación de la diagonal como objeto a la contemplación de la diagonal como elemento transformador del espacio (como propuesta ilusionista). Decrauzat nos induce a rememorar distintos enclaves de la historia del arte abstracto, mezclando métodos y formas heredadas de movimientos como la abstracción postpictórica, el minimalismo o el op art. Como iremos viendo, la radicalidad de su obra reside en transitar por distintos hitos de la tradición del arte abstracto geométrico presentándola de forma fragmentada ante nosotros. Lo hace copiando sus formas y sus estrategias, haciéndolas coexistir en un mismo plano, y colisionando postulaciones que históricamente estuvieron enfrentadas.

Es interesante rescatar algunas de las declaraciones de intenciones que definieron el arte minimalista de los años 1960 para ver las distancias respecto al trabajo de Decrauzat. Lourdes Peñaranda Quintero analiza, en su tesis doctoral titulada Donald Judd ilusionista (2010), la gestación del minimalismo Norteamericano durante la década de los años 1960 mediante el análisis de textos de artistas y otros agentes implicados en la época, como los críticos Lawrence Alloway, Lucy Lippard, Barbara Rose o Michael Fried. De esa forma, Pañaranda (2010) articula su recorrido prestando especial atención a la figura de Donald Judd, que fue un pilar fundamental a la hora de dibujar las bases conceptuales del minimalismo.

En primera instancia, según Peñaranda (2010), si algo caracterizó el arte 
minimalista fue la ruptura conceptual que generó respecto a la tradición del arte geométrico europeo de las primeras vanguardias artísticas y respecto a tendencias como el action painting también de los años 1960, en las cuales la subjetividad del artista permanecía muy presente y ejercía como energía articuladora para la formalización de la obra. Peñaranda (2010) escribe al respecto:

[...] es Black, White and Gray la primera exposición colectiva directamente identificada como minimalista que se realiza en un museo, el Wadsworth Athenaeum, en Hartford, Connecticut, en 1964, organizada por Samuel Wagstaff. La exposición incluía 22 artistas de diferentes generaciones y tendencias que se relacionaban por una supuesta afinidad basada en la ausencia de color; entre ellos se encontraban personajes tan variados como: Newman y Reinhardt; Stella, Johns, Rauschenberg, Twombly, Warhol, Lightenstein, Dine e Indiana; Kelly, Agnes Martin, Liberman y Parker; Morris, Truitt, Flavin y Tony Smith; junto con George Brecht, James Lee Byars, Robert Moskowitz y Jean Follet. [...]. Era un intento de Wagstaff por presentar la nuevas propuestas y estética de los sesenta, que reaccionaban ante las alusiones de sensibilidad del expresionismo y el action painting. (p.8)

Es en este sentido que el minimalismo, además de caracterizarse por la aparente simplicidad de sus formas reducidas al máximo grado de inexpresión subjetiva, introdujo también procesos de industrialización en su producción. Así, determinó una nueva forma de hacer y abrió una nueva perspectiva desde la que abordar la obra artística, mediante el desligamiento de cualquier marco de referencia que mantuviera un diálogo ajeno a la propia fiscalidad de la obra. Este era un principio diametralmente opuesto a la propuesta de Decrauzat. En ese sentido es interesante rescatar de la mano de Pañaranda (2010) la opinión de Donald Judd refiriéndose a la exposición Black, White and Grey de 1964:

El texto de Judd es mayoritariamente descriptivo; sin embargo asume una posición y establece algunas diferencias. Para Judd (2005:118), las propuestas de Robert Morris, Robert Rauschenberg y George Brecht, constituyen las más extremas en cuanto a la actitud inclusiva de sus obras y la cercanía a la inexistencia, a la presentación de la nada con objetos claramente identificados como arte. [...]. Pero son Flavin y Stella, los que para Judd (2005: 119), conforman las propuestas más complejas de la muestra, ya que se relacionan directamente con las intenciones de la neutralidad de la misma, [...]. Judd establece también 
tres precedentes a la nueva actitud. Las pinturas de Ad Reinhardt por su cercanía a la nada (2005:118), [...]. Las obras de Jasper Johns, a quien identifica más con Morris y Brecht por el manejo de la existencia del arte en la mínima expresión del objeto cotidiano. (pp.8-10)

La idea de que la obra haga referencia a sí misma y se agote en sí misma a la vez es una idea capital para entender el espíritu del minimalismo, y para entender el giro conceptual que propone el trabajo de Decrauzat. En esa misma línea, Donald Judd desarrolló la idea de que una obra debe ser "interesante de mirar". Así lo especificaba en su texto Specific Objects, publicado por el mismo Judd en 1965 en el Arts Yearbook, número 8, que Pañaranda recupera con las palabras de Judd, 1965,:

[...] antes la calidad se alcanzaba a través de la posible complejidad de los elementos compositivos o narrativos, ahora esta complejidad y calidad no se expresa literalmente, sino a través de su reducción a una única totalidad que es lo que hace que la obra sea interesante de mirar. (Peñaranda, 2010, p.17)

Decrauzat, por el contrario, realiza precisamente lo opuesto: su obra llega a la complejidad, no a partir de la lectura de cada pieza por separado, sino a partir de la colisión de las partes, es decir, a partir de la lectura fragmentada de las alusiones dispares que el conjunto de sus obras señalan. Si el minimalismo predicaba que la obra hiciera referencia a sí misma, el trabajo de Decrauzat se despliega "extra-referencialmente", a través de las partículas estilísticas de cada una de las obras que conforman sus exposiciones.

Siguiendo con la exposición On the retina (2011) de Decrauzat que nos ocupa, la obra Méthode d'objectivation critique, (dispersion) (2011) (Figuras $1,2,7$ y 8 ) se despliega y se suma a lo largo del espacio central de la exposición. Se trata de varios elementos repartidos por el suelo a través de los distintos espacios expositivos. Estos elementos con forma orgánica y moldeados en hormigón son fragmentos de una silla Thonet $n^{\circ} 14$. El diseño de la silla original Thonet $n^{\circ} 14$ recibió en 1867 una medalla de oro en la Exposición Mundial de París, producida a finales de la década de 1850 por la compañía Thonet. Se trata de una silla constituida por seis piezas de madera de haya curvada mediante vapor. Dicha silla fue elogiada por su fácil ensamblaje, hecho que facilitaba el ahorro de espacio durante su transporte para ser comercializada.

Lo que propone Decrauzat es desmontar y luego ensamblar distintas partes de la silla para construir nuevas formas. Este ejercicio de desmontaje y posterior 
montaje le sirve al artista para articular otro de sus principales modos de operar, presentando sobre un escenario constituido por elementos irreconocibles un elemento en apariencia abstracto pero que hace referencia directa a un objeto real y de orden utilitario. Este hecho se repite constantemente en la obra de Decrauzat y es, como podremos ver, la cualidad específica que reactiva de forma renovada el modo en que se nos presenta la obra abstracta.

Una tercera sala acoge los tres dibujos D.T.A.B.T.W.H.A.H.E., (2011) (Figura 3), realizados en tinta sobre papel y a doble cara, colocados perpendicularmente a la pared de manera que se pueden ver las dos caras del dibujo y es posible recorrerlo tridimensionalmente. Las letras del título corresponden a las iniciales de las palabras que conforman la frase "Does the angle between two walls have a happy ending". Frase a su vez extraída del texto de un collage de 1967 realizado por J. G. Ballard y publicado en el número 33 de la revista británica Ambit. En dicho collage vemos el texto y el dibujo en blanco y negro de una mujer masturbándose. El título del dibujo sirve a Decrauzat para volver a colocar un sustrato, una información específica, una referencia bajo la superficie geométrica de los dibujos.

Por otra parte, el recurso formal de los dibujos de Decrauzat están inspirados en la obra del artista polaco Waclaw Szpakowski (1883-1973). Szpakowski fue un artista, arquitecto y fotógrafo que nunca se dedicó al arte profesionalmente, y que solamente empezó a darse a conocer a finales de su vida, gracias a una exposición colectiva en 1968 en el Museo nacional Sztuki de Lodz, y posteriormente en 1994 con dos exposiciones más importantes, una en el Museo Nacional de Warsaw y la otra en el Museo Willem Hack de Ludwigshafen (Johnson, T; Jedrzejewski, F, 2013, p.8). Más recientemente, tres de sus obras han sido presentadas en la exposición Inventing Abstraction, 1910-1925 (2012 - 2013) en el MoMa de Nueva York. Son conocidos sus trabajos en tinta sobre papel, en los que realiza unas composiciones geométricas y laberínticas sin fin, donde su resultado final deriva en una suerte de efecto óptico sobre el espectador. La obra de Szpakowski sigue el eje argumental de la concepción moderna de un orden universal que puede ser expresado a través de la geometría y la matemática, y así lo recuerda Janusz Zagrodzki: "He tried to grasp and formulate the rules of geometry of the world, he regarded the rules of symmetry and repetitions to be the main features characterizing both unanimated and animated world" (Zagrodzki, s.f). Intentó entender y formular las reglas de la geometría del mundo, consideró las reglas de la simetría y las repeticiones como rasgos principales que caracterizan ambos mundos, el animado y el inanimado. 
Decrauzat yuxtapone a J.G. Ballard contra Szpakowski: a la pregunta "Does the angle between two walls have a happy ending?", la respuesta de los laberintos infinitos a doble cara de Decrauzat parece inducir al espectador a hallar una respuesta que será, por lo menos, extraña. El hecho de confrontar al espectador con dos imágenes paralelas tan opuestas gramaticalmente, en dos categorías tan dispares - por un lado, una mujer masturbándose, y por el otro, unas imágenes de geometrías de laberintos infinitos - sólo puede conducir a plantearse dos posibles deducciones. La primera, que el artista intenta generar algún tipo de alegoría simbólica acerca del gesto de masturbarse como momento infinito de placer, o por el contrario, que está intentando despotenciar e ironizar acerca de las cargas ideológicas iniciales de los trabajos de Szpakowski mediante la interferencia [la mujer masturbándose] sobre la pulcritud de las ideas germinales del artista polaco. En cualquier caso, Decrauzat presenta las composiciones geométricas como algo que quiere desvincular de su referencia inicial, para decirnos, al fin y al cabo, que lo que se ve no es lo que uno piensa que conoce.

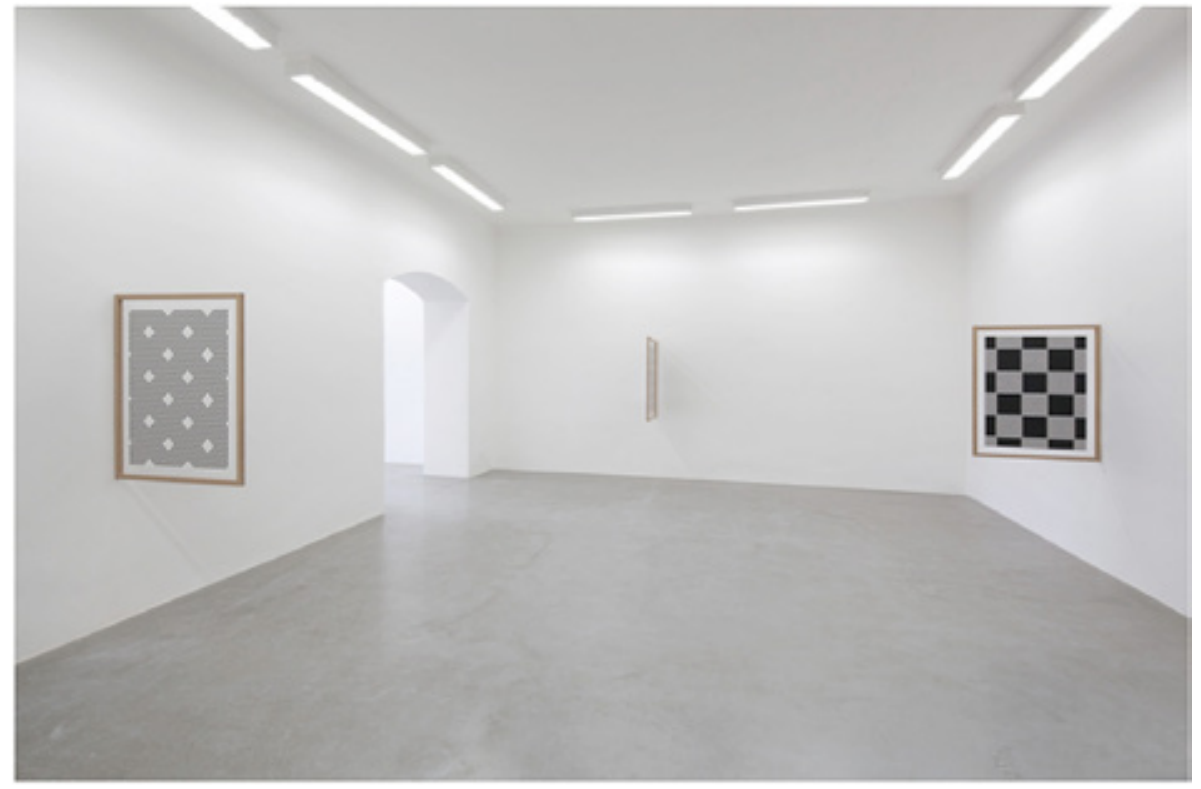

Figura 3. Philippe Decrauzat. Vistas de la exposición On the retina (2011). House of Art Ceské Budejovice, República Checa. Foto: Jan Mahr. Cortesía del artista y de la galería Parra \& Romero. (C) 
La pieza que cierra la exposición On the retina (2011) es la proyección de la película en $16 \mathrm{~mm}$ Screen-o-scope (2010) (Figura 4). La película está montada a partir de escenas de la película Rashomon (1950) del director Akira Kurosawa. Decrauzat selecciona las escenas de la película en las que la cámara enfoca hacia el sol que irradia entre las ramas de los árboles. El fuerte contraste en blanco y negro de la película de Decrauzat transforma el film en una sinfonía de luz parpadeante, de una manera cada vez más intensa, hasta abstraerse de su referencia inicial. La intermitencia de la película desestabiliza nuestra mirada haciéndola vibrar, consiguiendo un efecto ilusorio sobre nuestra percepción.

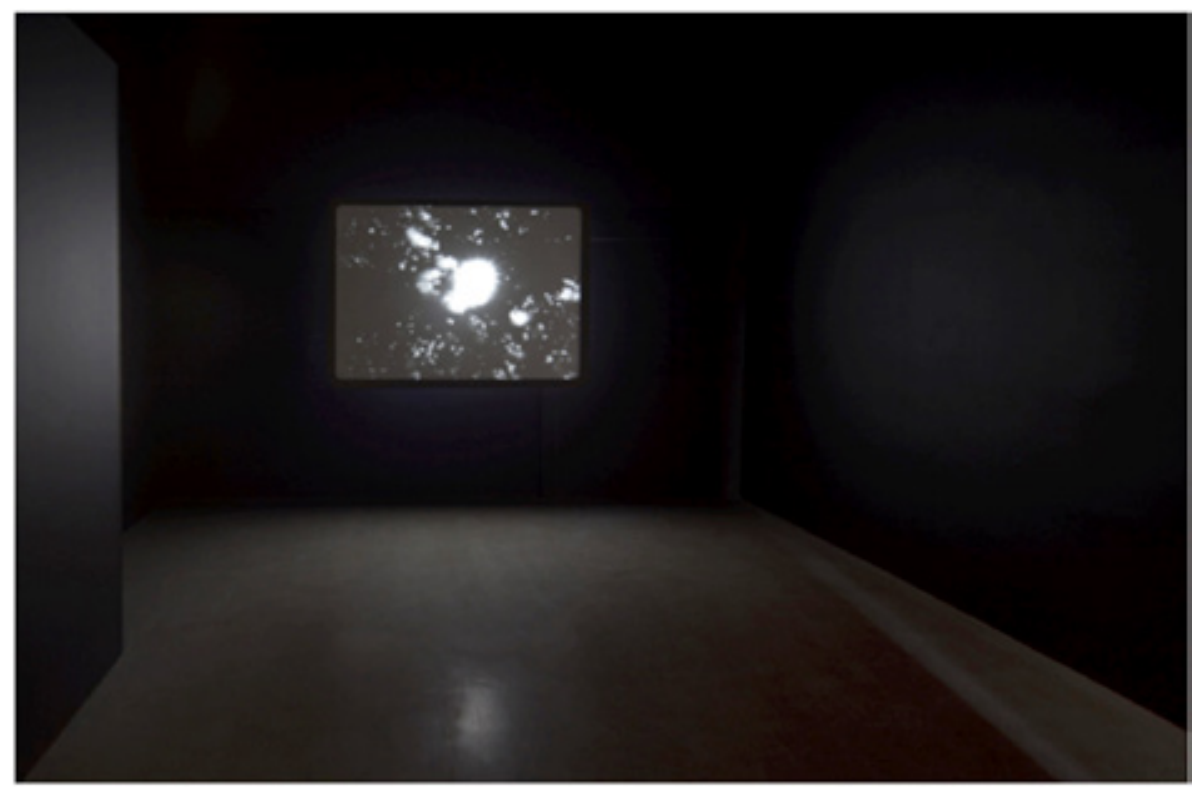

Figura 4. Philippe Decrauzat. Vistas de la exposición On the retina (2011). House of Art Ceské Budejovice, República Checa. Foto: Jan Mahr. Cortesía del artista y de la galería Parra \& Romero. (C) 


\section{Un Muro de La Villa Malaparte como Objeto Minimalista}

En la segunda exposición, Corps Flottants (2013), realizada en la galería Madrileña Parra \& Romero, Decrauzat nos presenta tres bloques de piezas repartidos en dos espacios. En el primer espacio de la galería nos encontramos una pieza escultórica, Light space modulator (2002), formada por dos tubos de acero en forma de " $\mathrm{T}$ " invertida, colgada del techo y con dos luces parpadeantes en los extremos de la superficie horizontal de la "T". En el centro del espacio principal de la galería nos encontramos una escultura de grandes dimensiones y fragmentada en dos partes. Myodesopsia (2012) (Figura 5), cruza e invade todo el espacio central de la galería, mientras cuelgan sobre las paredes tres pinturas de la serie On cover (2012) (Figura 9 y 10), constituidas por diagonales rojas y azules, entrecruzadas y creando distintos ritmos visuales ondulatorios.

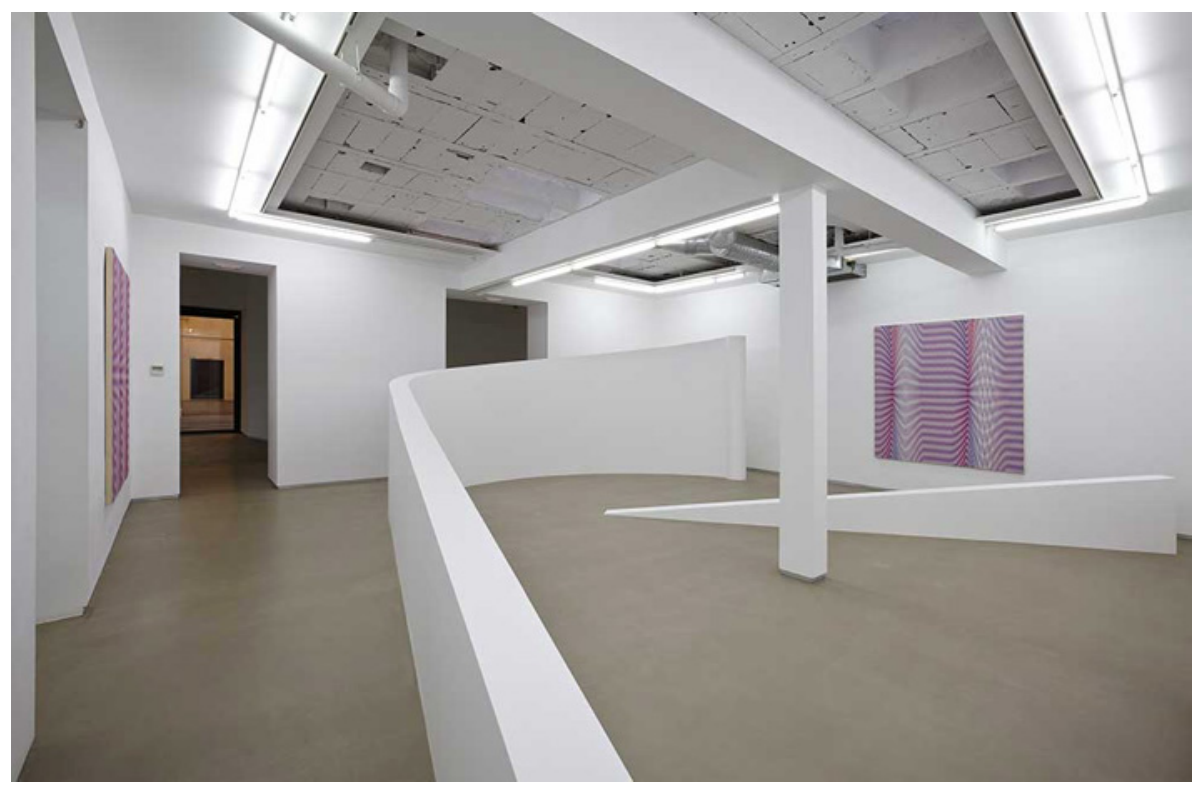

Figura 5. Philippe Decrauzat. Vistas de la exposición Corps Flottant (2011). Galería Parra Romero, Madrid. Cortesía del artista y de la galería Parra \& Romero. (C)

Una vez más, los trabajos de Decrauzat vuelven hacer referencia a algo que queda fuera de la autorreferencialidad del propio lenguaje abstracto aparente. En el caso de la obra Light space modulator (2002), la primera pieza 
que nos encontramos en la exposición, el ritmo de parpadeo de las dos luces no es un ritmo aleatorio, sino que es un bucle formado por una secuencia de once minutos. Esta partitura rítmica está inspirada en una secuencia de la película de terror El exorcista II (1973) de John Boorman y Rospo Pallenberg. En dicha secuencia, los dos protagonistas son hipnotizados por una lámpara que se sincroniza paulatinamente al ritmo cardíaco de los personajes. En este caso, el efecto es el mismo que se da en la película Screen-o-scope (2010) (Figura 4), donde el artista selecciona una referencia cinematográfica y la transforma en pulsaciones lumínicas, en algo puramente rítmico. Siguiendo el recorrido de la exposición y volviendo a la sala principal de la galería, se encuentra la escultura principal de la exposición, Myodesopsia (2012) (Figura 5), una gran línea recta que nace desde un punto cero y va alzándose hasta acabar curvándose.

Myodesopsia (2012) (Figura 5) es una reproducción de un elemento arquitectónico existente, pero representado en dos partes en el espacio expositivo. Los dos fragmentos están inspirados en una parte arquitectónica de la la Villa Malaparte (Figura 6), situada en un acantilado frente al mar Mediterráneo en Italia. Concretamente, se trata de un muro que yace en la terraza-solárium de la casa. La casa fue diseñada por el escritor Curzio Malaparte en 1937. A primera vista, el gran elemento geométrico que Decrauzat presenta en la galería recuerda a las esculturas minimalistas de Robert Morris Seven geometric plywood structures painted grey (1964), por su simplicidad objetual y uniformidad. Sin embargo, el juego referencial de Decrauzat, a pesar de la imponente y clara referencia del objeto al minimalismo, añade una segunda referencia fuera de ese principio histórico, añade al objeto una cita, una nota al margen que nos dirige a un muro que yace sobre la terraza de una casa que está construida en un acantilado frente al mar. Por otra parte, el título de la pieza "Myodesopsia", en español "Miodesopsias", es un término que también se conoce como "cuerpos flotantes" [título de la muestra], un efecto visual que se da en el propio ojo, debido muchas veces al envejecimiento natural del músculo ocular. Los "cuerpos flotantes" son un conjunto de manchas o filamentos en el campo visual, que se presenta mediante la aparición de opacidades en el humor vítreo, proyectándose la sombra de estas sobre la retina, provocando así la proyección de estos pequeños elementos cuando el sujeto está mirando. Esa idea es una interesante metáfora de cómo el objeto presentado, Myodesopsia (2012) (Figura 5), puede ser entendido como un "cuerpo flotante" para nuestra mirada, un cuerpo, un objeto que no se nos presenta de forma clara, nítida, es un objeto minimalista pero a su vez no 
lo es. ¿Qué es exactamente? ¿Es una maqueta? Decrauzat es consciente de estas preguntas y utiliza esa interferencia como principio estructural de su trabajo. Una vez más nos revela las operaciones que se dan inevitablemente en los procesos cognitivos de entendimiento, en los cuales interviene inexorablemente la memoria que activamos sobre la disciplina "arte".

Es interesante rescatar en este punto la visión que dio Michael Fried respecto al minimalismo en el texto Arte y objetualidad publicado inicialmente en 1967 en la revista Artforum. Michael Fried arremetía contra el minimalismo a partir de una reflexión concebida desde la idea de un "arte puro", frente a las nuevas formas de relación con el espectador que la obra minimalista estaba proponiendo. En la introducción del texto de Michael Fried (1967/2012), Carolina Benavente Morales expone:

El rechazo del arte minimal por Michael Fried obedece a su defensa formalista de un arte "puro" cuyo foco consistiría en la elaboración de imágenes. Y, en efecto, las vanguardias se despojan crecientemente de ellas o bien las usan como parte de una relación artística que, en el arte minimal, todavía se lleva a cabo en una sala, pero que pronto se expande hacia la naturaleza (land art) y la sociedad (arte relacional, arte contextual, net art, etc.). (Fried, 1967/2012 p.6)

Michael Fried (1967/2012) tacha al minimalismo de "no arte", respecto al "arte puro" que se despliega mediante el uso de las formas y de las combinaciones sintácticas que puedan generar entre sí los elementos que conforman una obra, obteniendo resultados que abren consideraciones de color, gesto, línea, mancha, ritmo, etc. Desde ese argumento, Fried alaba el trabajo de Anthony Caro por el uso que hace de los elementos industriales, con un fin radicalmente opuesto al minimalismo. Según Fried, Caro emplea tubos, vigas, travesaños y cilindros para ensamblarlos compositivamente como si de una sinfonía se tratase (Fried, 1967/2012 p.13). Ese uso de los elementos industriales a partir de sus yuxtaposiciones confiere a la obra un alejamiento de los atributos individuales de los materiales con los que la obra está realizada, y es este factor precisamente lo que aleja al trabajo de Caro del minimalismo.

Cabe decir que el formalismo iniciado a finales del siglo XIX había constituido un bloque discursivo y hegemónico en Estados Unidos, con el expresionismo abstracto como su máximo exponente en la década de los 1960 y bajo el fundamento teórico del mentor de Michael Fried, el famoso crítico Clement Greenberg. En ese marco y desde una perspectiva formalista, Fried 
detectaba acertadamente la ruptura que el minimalismo estaba proponiendo: la obra minimalista estaba vacía, su peso de significación descansaba en la interpelación de su forma exterior con el espectador y de la presencia del material como tal. De esta manera, las obras requerirían del espectador para activarse, para ser un simple objeto permanentemente en presente. Para Fried (1967/2012), el arte minimalista, o como lo nombra en su texto, "arte literalista", incide en la exploración de lo relativo a su figura, es decir a lo relativo a su forma exterior:

[...] Judd y Morris afirman los valores de la totalidad, la singularidad y la indivisibilidad - del ser de una obra, lo más cercano posible a "una cosa", a un "objeto específico" singular. Morris le dedica una atención considerable al "uso de formas de gestalt fuerte o de tipo unitario, con el fin de evitar la división", mientras que Judd es el principal interesado en el tipo de totalidad que puede alcanzarse mediante la repetición de unidades idénticas. El orden que opera en sus piezas, tal como lo observó una vez a propósito de las pinturas franjeadas de Stella, "es simplemente orden, similar al de la continuidad, una cosa tras otra". No obstante, tanto para Judd como para Morris, el factor crítico es la figura. Las "formas unitarias" de Morris son poliedros que se resisten a ser captados como si fuesen algo distinto de una figura singular: la gestalt es, simplemente, "la figura constante, conocida". Y en sí misma, en su sistema, la figura es "el valor escultórico más importante". [...] Así, la figura es el objeto: en cualquier caso, lo que asegura la integridad del objeto es la singularidad de la figura. Es este énfasis en la figura, creo, lo que valida la impresión, compartida por numerosos críticos, según la cual las piezas de Judd y Morris están “huecas”. (Fried, 1967/2012 p.6)

Fried (1967/2012) detecta que ese desplazamiento hacia el exterior de la obra, hacia su "figura", junto con la tendencia hacía los grandes volúmenes de las obras minimalistas, promovía la involucración del espectador como parte imprescindible para su concepción y para la transformación de la obra en un objeto más del mundo. Estas cualidades son las que para Fried llevan al minimalismo a ser un arte literalista y teatral, que promueve ante todo un desplazamiento del arte hacia la pura objetualidad. En estos términos posiciona Fried (1967/2012) su tesis:

[...] la adhesión literalista a la objetualidad no es más que la defensa de un nuevo género de teatro; y el teatro constituye ahora la negación del arte. La sensibilidad literalista es teatral porque, para comenzar, 
le preocupan las circunstancias concretas en las que el espectador se encuentra con la obra literalista. Morris lo plantea en forma explícita. Mientras que en el arte anterior 'lo que debía obtenerse de la obra se localizaba estrictamente en su interior', la experiencia del arte literal es la de un objeto en situación -objeto que, casi por definición, incluye al espectador [...]. (p.8)

Volviendo al caso del muro en forma de obra minimalista de Decrauzat, Myodesopsia (2012) (Figura 5) lo podemos entender, visto desde la perspectiva de Fried, precisamente como lo contrario a una forma "hueca": es una reproducción de un muro, pero cabe también decir, y es en este punto donde la propuesta de Decrauzat se complejiza, que Myodesopsia (2012) (Figura 5) es también una referencia que señala al minimalismo como disciplina.

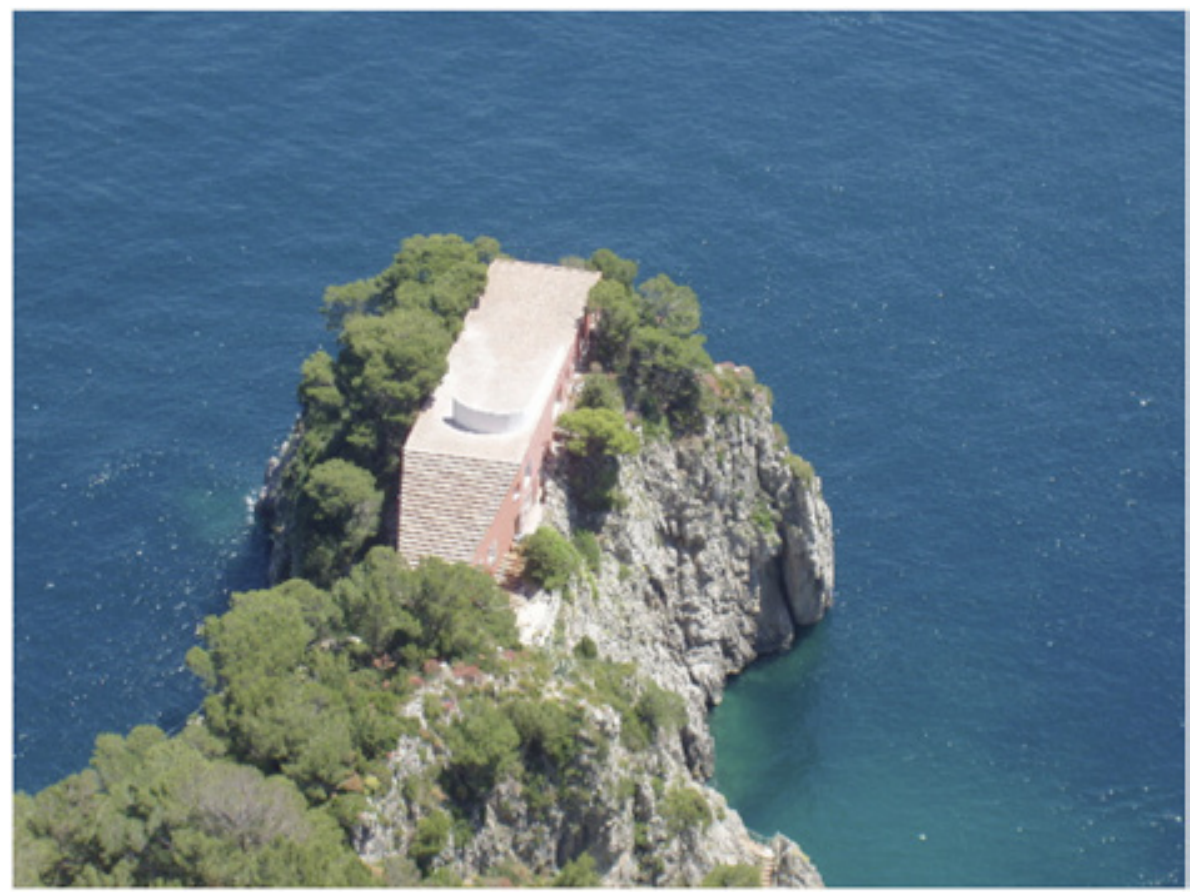

Figura 6. Villa Malaparte. Capri, Italia. 2005. Foto: Peter Schüle. En Wikipedia. Recuperado el 17 de julio de 2013 de http://de.wikipedia.org/wiki/Villa_Malaparte\#mediaviewer/File:Villa_Malaparte.jpg 
Siguiendo nuestro recorrido, el tercer elemento de la exposición Corps Flottants (2013) se conforma de tres pinturas de la serie On cover (2012) (Figura 9 y 10). En una entrevista realizada por Guillermo Parra Romero el 1 de febrero del 2013, coincidiendo con su exposición Corps Flottants (2013) y publicada en la página Web de la galería madrileña, Decrauzat describe las tres pinturas de la siguiente forma:

Como es a menudo el caso, preexiste una imagen. En este caso concreto, se trata de la portada de la revista de divulgación científica Scientific American de 1963, dedicada a los 'moirés patterns'. El artículo trata del uso que hace la ciencia de estas representaciones gráficas, demostrando la capacidad que tienen para revelar, en una secuencia regular, variaciones, cambios de ritmo, o interferencias. (Galería Parra Romero, 2013)

Decrauzat sigue hablando refiriéndose a la serie de pinturas de la exposición On the retina (2011):

Mi trabajo alrededor de esta ilustración empezó años atrás, cuando tomó primero la forma de una pintura mural que se desarrollaba de manera cinemática en el espacio de exposición de Le Plateau en París (2011). En paralelo, había empezado aislando algunos fragmentos de esta imagen para realizar shaped canvas monocromos, simple composición a base de diagonales, de intersecciones o de elementos simples; letras, signos, formas abstractas que se desarrollan en una gramática formal por una orientación escópica; permutaciones que puntuaban varias de mis exposiciones. (Galería Parra Romero, 2013)

Es interesante esta declaración de Decrauzat porque confirma el uso que el artista hace del minimalismo y del op art, que en este caso, parece indicar que es puramente a modo de cita. El punto de referencia que nos describe es un documento de divulgación científica que explica las formas posibles en que las diagonales pueden generar distintas gramáticas visuales. Decrauzat sigue en la entrevista y explica el punto del proceso en que se encuentra actualmente:

La última etapa sale ahora mismo de la imprenta. Mathieu Copeland me ha invitado a realizar la portada del catálogo 'Gustav Metzger, Autocreative Art'. Confrontado a un nuevo contexto y de vuelta a su soporte de origen, este 'expanded pattern' está cargado con todas las etapas precedentes. La circulación paranoica de una imagen. (Galería Parra Romero, 2013) 
La última frase de la cita nos parece reveladora: "la circulación paranoica de una imagen", o lo que sería lo mismo, una amplia gama de modos con los que representar diagonales sobre distintos soportes, ya sea sobre un muro, sobre un lienzo o sobre un papel impreso. Es importante visualizar ahora dos imágenes de dos exposiciones, Anisotropy (2011) (Figura 7) y On the retina (2011), en las que podemos observar su parecido: se trata de dos imágenes casi idénticas, con un fondo distinto. Además se repite la silla explosionada en fragmentos por el suelo de ambas exposiciones, y tras los restos de hormigón, en su fondo las diagonales, en una exposición como sistema ilusorio [op art], $\mathrm{y}$ en la otra como sistema objetual [minimalismo].

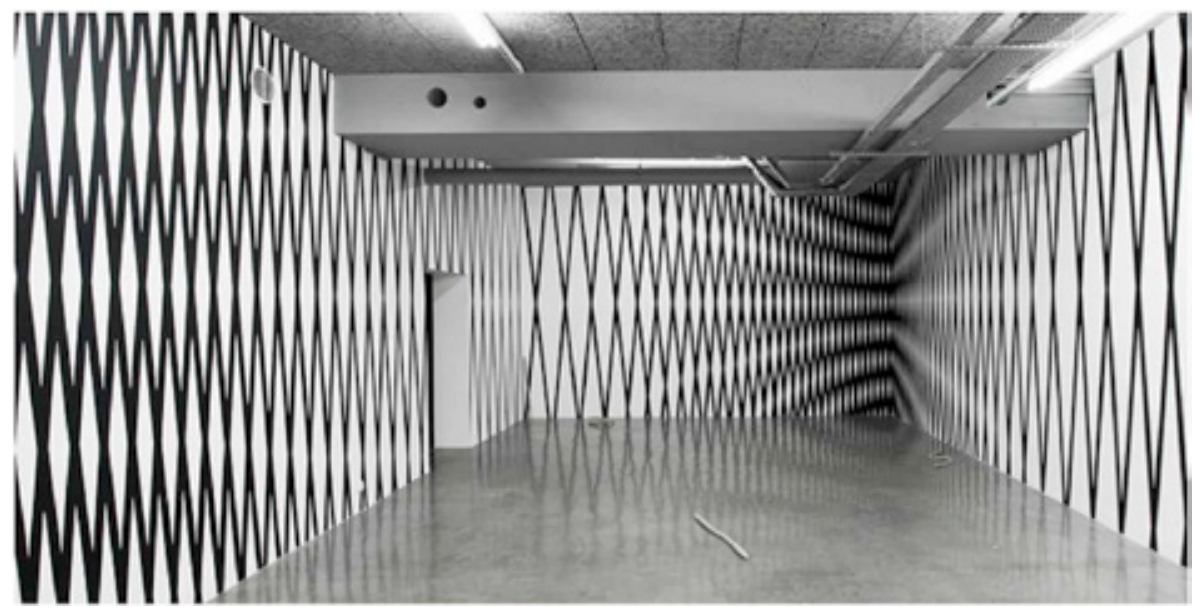

Figura 7. Philippe Decrauzat. Vistas de la exposición Anisotropy (2011). Le Plateau/ FRAC Ile de France, Paris. Foto: Martin Argyroglo. Cortesía del artista y de la galería Parra \& Romero. () 


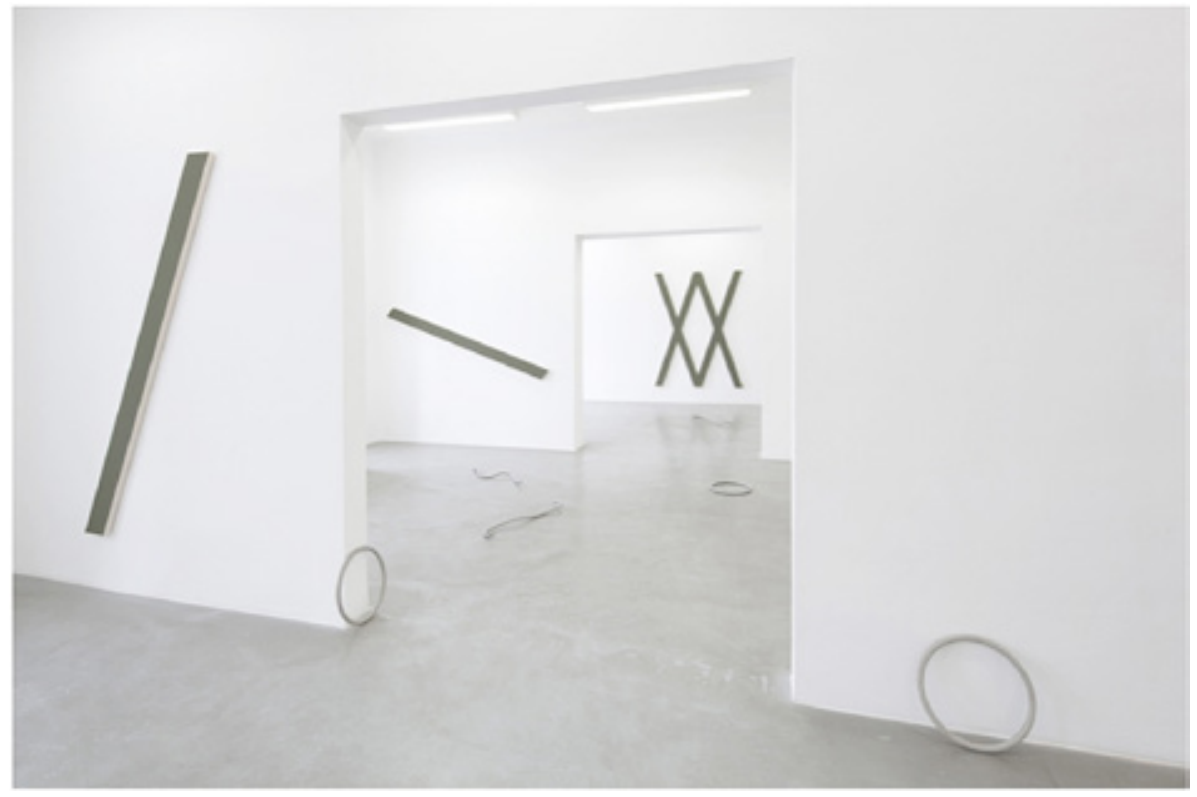

Figura 8. Philippe Decrauzat. Vistas de la exposición On the retina (2011). House of Art Ceské Budejovice, República Checa. Foto: Jan Mahr. Cortesía del artista y de la galería Parra \& Romero. (C)

Nikos Stangos recoge en su libro Conceptos del arte moderno un capítulo titulado Op Art escrito por Jasia Reichardt en 1966. En el texto, Reichardt (1966) se centra en describir los principales rasgos del op art, los cuales se concentran en la descripción de una práctica basada en la exploración de las posibilidades perceptivas del ojo que derivan en fenómenos ilusorios sobre el espectador. Refiriéndose a ello Reichardt (1966) describe:

En esencia posee la cualidad dinámica que provoca imágenes y sensaciones ilusorias en el espectador, ya sean que estas ocurran en la estructura física real del ojo o en el cerebro mismo. De esto uno puede deducir que el op art tiene que ver de manera fundamental y significativa, con la ilusión. (p.237)

La autora lee como precedentes del op art la técnica pictórica empleada por algunos impresionistas y postimpresionistas, ejemplificando el uso que 
hacía Seurat de la mezcla de colores aplicados directamente sobre el lienzo, "permitiendo que el ojo mezcle los puntos de color a cierta distancia" (Reichardt, 1966, p.238). Ese factor, en el que la actividad de las condiciones físicas de la percepción participan de la lectura de la obra, es el que, para Reichard, hace que el op art sea ante todo una práctica donde la técnica y el tema confluyen en el mismo plano de significación. La autora ilustra su texto mediante ejemplos del trabajo de distintos artistas de la década de los años 1960 como Bridget Riley, Victor Vasarely, Albers, Cruz-Díez y J.R. Soto. Recogiendo las propias palabras de Albers, Reichard suscribe: "Ha demostrado lo engañoso que un color puede ser, cómo es posible hacer que diferentes colores parezcan idénticos y tres colores pueden leerse como dos o, a la inversa, como cuatro" (Reichardt, 1966, p.237). Refiriéndose a CruzDíez y J.R. Soto, comenta: "las obras de Cruz-Díez y J.R. Soto, donde alguna ilusión de movimiento tiene lugar mientras el espectador está en movimiento y la obra permanece inmóvil" (Reichardt, 1966, p.237).

Es atinada la lectura que realiza Jasia Reichardt (1966) acerca del op art porque lo sitúa en un campo de experimentación formal cuyo objetivo último es el proponer una discrepancia entre las condiciones físicas de las obras y sus modos de recepción paradójicas sobre las condiciones físicas de la naturaleza humana. Posicionamiento, radicalmente opuesto al del minimalista Donald Judd, quien coloca su práctica en el rechazo a los modelos ilusionistas de representación, y radicalmente en sintonía formal con las pinturas On cover (2012) (Figuras 9 y 10) de Decrauzat.

Esta vez, Decrauzat alude al op art con sus pinturas On cover (2012) (Figuras 9 y 10). A diferencia de la alusión "reversa" que realiza con Myodesopsia (2012) (Figura 5) sobre el minimalismo, con el op art establece un hilo conductor sin interrupciones respecto a sus referentes más obvios, como por ejemplo con el trabajo de Bridget Riley.

Es en este programa de alusiones directas, de guiños y de giros, con los que Decrauzat transita por los distintos enclaves de la historia del arte. Pero si no solamente ponemos en el mismo plano las similitudes formales de los trabajos particulares de Decrauzat con sus referencias más evidentes, sino que además intentamos entender una visión conjunta de las distintas citas, probando de establecer un común denominador, probablemente hallaremos una nueva vía de lectura sobre su práctica, más acorde con el modo en que articulamos el conocimiento que poseemos sobre el arte y sus posibles líneas de despliegue y articulación, que con una simple práctica fundamentada en la repetición de códigos. 
226 Ricardo Trigo - Abstracción Referencial. Philippe Decrauzat

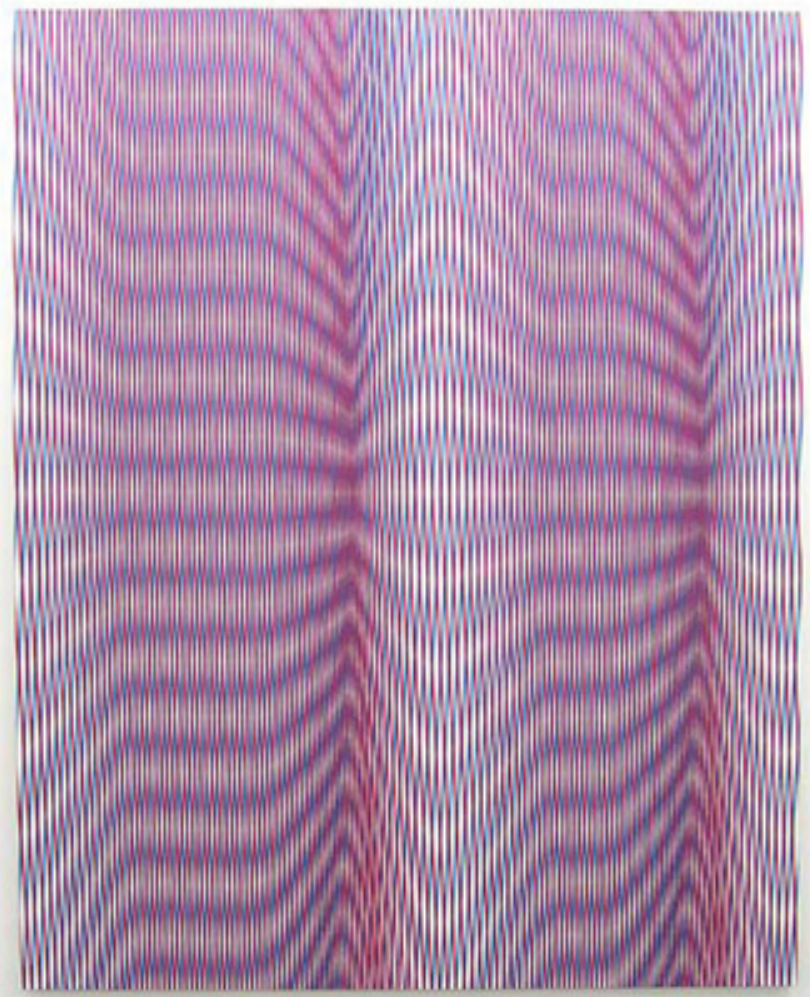

Figura 9. Philippe Decrauzat. On cover (2013). Acrílico sobre lienzo. 200 x $180 \mathrm{~cm}$. Cortesía del artista y de la galería Parra \& Romero. (C) 


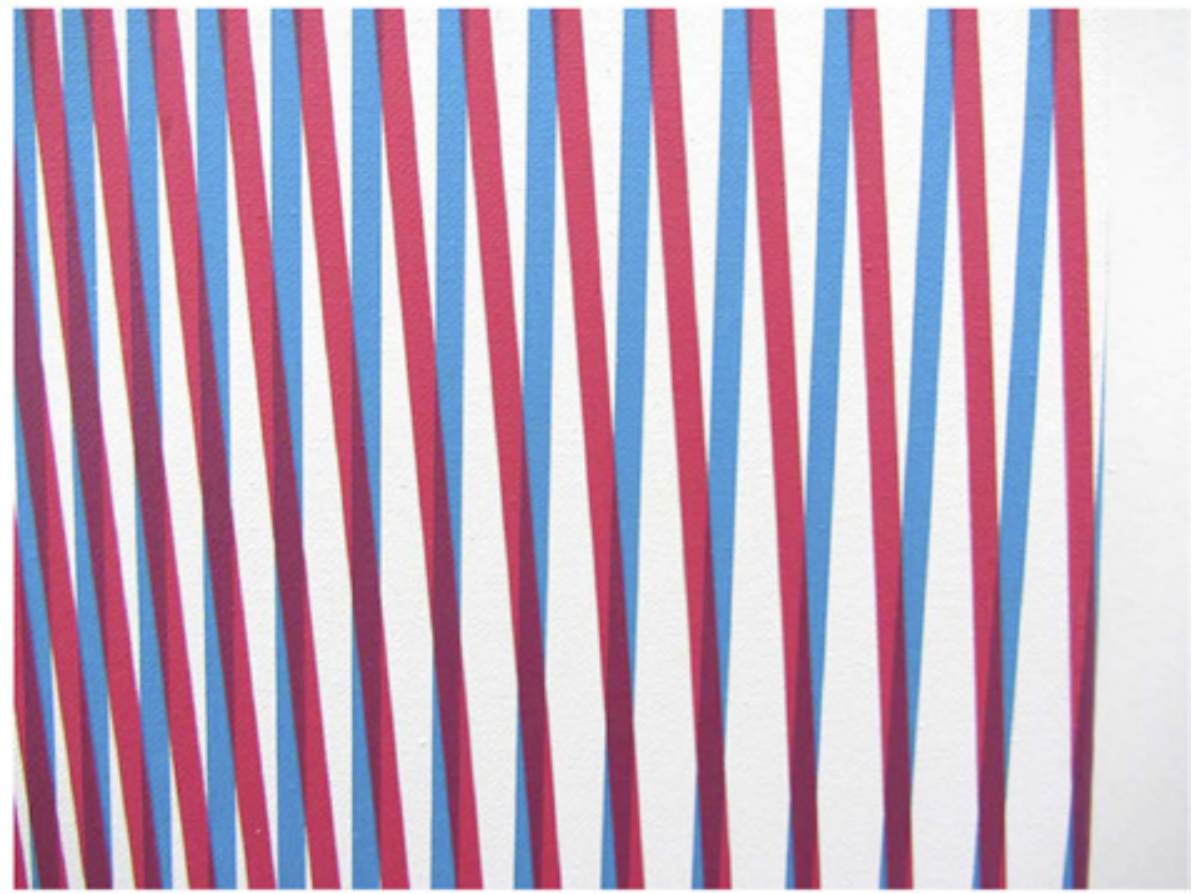

Figura 10. Philippe Decrauzat. On cover (2013), (Detalle). Acrílico sobre lienzo. 200 x $180 \mathrm{~cm}$. Cortesía del artista y de la galería Parra \& Romero. (C)

\section{Disciplinas Homologadas}

En el capítulo El quid del minimalismo (pp.39-74) de Hal Foster (2001) dentro de su libro titulado El retorno de lo real, el minimalismo está entendido como un acontecimiento que abrió una nueva vía de exploración para el arte, ya que entrados en el siglo XXI todavía perdura abierta y latente (p.40). Para Foster (2001) el minimalismo inauguró el rechazo del antropomorfismo en las formas del arte y el desplazamiento de la escultura fuera de su pedestal, es decir, la recolocación de esta entre los objetos del mundo. Produciéndose así el desplazamiento del espectador fuera de la red de seguridad que el arte tradicional le otorgaba, y colocándolo por otra parte como eje central durante el transcurso de la experiencia espacial de la obra. Y lo que es más importante, el minimalismo recuperó el espíritu dadaísta y Duchampiano al "desafiar a la institución arte" (Foster, 2001, p.42). 
Foster (2001) sostiene que sobre la concepción generalizada acerca del minimalismo existen dos errores. Uno es decir que el minimalismo es reduccionista y el otro es decir que es idealista (p.42). Citando a Rosalind Krauss, 1973, Foster (2001) reafirma: "De modo que la apuesta del minimalismo es la naturaleza del significado y el status del sujeto, cosas ambas que se sostiene que son públicas, no privadas, producidas en conexión física con el mundo real, no en un espacio mental de la concepción idealista" (p.42). Cuando el minimalismo evidenció la necesidad de la temporalidad durante la percepción de la obra, se abrió la amenaza hacia "el orden disciplinario de la estética moderna en la que se considera que el arte visual es estrictamente espacial"' (Foster, 2001, p.46). De ahí que, el minimalismo para Foster (2001) está enlazado con el arte procesual y la performance. Atributos que alertaron a las posiciones más rígidas a favor del formalismo, como por ejemplo, la posición de Michael Fried, que recogimos anteriormente de su texto Arte y objetualidad. O como nos recuerda el mismo Foster (2001), refiriéndose a otros defensores del formalismo:

Así el minimalismo, contradice los dos modelos dominantes del expresionismo abstracto, el artista como creador existencial (propuesto por Harold Rosenberg) y el artista como crítico formal (propuesto por Greenberg). Con ello desafía dos posiciones centrales en la estética moderna que estos dos modelos de artistas representan: la primera expresionista; la segunda formalista. (pp. 44-46)

En su obra, Foster (2001) se sirve de tres de los textos capitales para entender el minimalismo de la época de los años 1960 para desgranar lo que para él son una serie de malentendidos (p.48). Los textos en cuestión son: Objetos especificos de Donald Judd, 1965, Notas sobre escultura, Partes 1 y 2 de Robert Morris, 1966, y Arte y objetualidad de Michael Fried, 1967. En el caso de Donald Judd, Foster (2001) establece que el que una obra "tan sólo necesite ser interesante" se opone a la noción de "calidad" defendida por Greenberg. Pero sin embargo, Foster (2001) expone que son ideas que pueden llegar a converger:

Mientras que la calidad se juzga en relación con los niveles no sólo de los maestros antiguos sino de los grandes modernos, el interés lo provoca la puesta a prueba de las categorías estéticas y la transgresión de las formas establecidas. En una palabra, la calidad es un criterio de la crítica normativa, un encomio otorgado al refinamiento estético; el 
interés es un término vanguardista, a menudo medido en términos de desbaratamiento epistemológico. También puede llegar a ser normativo. (p.50)

En el caso de Robert Morris, Foster (2001) señala la contradicción del discurso desarrollado por el artista. Morris, yuxtapone dos categorías en la noción de escultura. Una categoría está en sintonía con Donald Judd, y la otra con Michael Fried; una sería "la demanda de autonomía" (Foster, 2001, p.50) y la otra, "la demanda de literalidad" (Foster, 2001, p.50). Foster (2001) lo despliega así: "Morris primero define la escultura moderna en términos de minimalismo (es literal) y luego define el minimalismo en términos de la escultura moderna (es autónomo)" (p.52). Para Foster (2001) las declaraciones de intenciones de Robert Morris, reflejan las contradicciones de la época de los años 1960 respecto al discurso minimalista, porque su discurso entiende la expansión de la escultura como un "puro objeto" y a su vez, la expansión de ese nuevo límite de la escultura como si fuera un monumento a escala humana. Es decir que para Foster (2001), Robert Morris abre un nuevo espacio reflexivo sobre la nueva libertad de la escultura, espacio conformado por el binomio objeto/sujeto, e inaugura con ello tanto "la muerte del autor" (p.51), como "el nacimiento del espectador" (p.51).

Sobre Michael Fried, Hal Foster (2001) deduce la razón por la que Fried, tachaba al minimalismo de "no arte" en su texto Arte y objetualidad sería que el autor previó el desplazamiento del arte al campo expandido del objeto mundano y con ello vio desmoronarse los cimientos del proyecto formalista, de manera que "el viejo orden ilustrado de las artes (las artes temporales frente a las espaciales) es puesto en peligro" (Foster, 2001, p.55). Para Foster (2001) el minimalismo no sólo puso en jaque la autonomía del arte defendida por Fried, sino que también sacó a la luz los aparatos internos que soportaban el discurso formalista, un discurso basado en la "fe" y en la "convicción". Ambos conceptos tienen bajo la óptica de Fried, un común denominador: "corromper la creencia en el arte" (Foster, 2001, p.56). En ese sentido, Foster (2001) establece un paralelismo entre el discurso formalista de Fried y la religión, en tanto que Fried, acabara su texto con la sentencia espiritual "la presencia es la gracia” (p.56), ecuación desde la cual, el formalismo estaría basado en un modelo que funcionaría bajo los parámetros de la fe, y lo que quedaría fuera de ese estricto orden, no sería arte.

La conclusión de Foster (2001) la conforma el cruce de fuerzas entre las posiciones que defendían el arte como autonomía y las que inauguraron el 
arte como literalidad. Es en ese choque donde se establece el principal eje motor del minimalismo, porque con ello "el minimalismo aparece como un punto históricamente culminante en el que la autonomía formalista del arte es a la vez alcanzada y destruida" (Foster, 2001, p.58). El crítico establece de ese modo un hilo conductor entre las primeras vanguardias transgresoras y el minimalismo. Según Foster (2001) el desarrollo de las primeras vanguardias fue interrumpido inicialmente por el nazismo y el estalinismo, y décadas después en Norteamérica por la guerra fría, período este último en que la vanguardia transgresora quedó fuera de la institución bajo el dominio formalista liderado por Greenberg. Sin embargo, durante y con el minimalismo se genera una consciencia sobre ese marco dominante [el formalismo], y con ello, a partir de los años 1960, el minimalismo junto con el arte pop apuntan de nuevo a reflexionar sobre los aspectos contextuales del arte y sobre las nuevos paradigmas de la cultura de masas. Y de algún modo, eso converge en definitiva en una puesta en cuestión del dominio formalista. Foster (2001) citando a Peter Bürger, 1974, escribe:

El significado de la ruptura en la historia del arte que provocaron los movimientos de la vanguardia histórica (escribe Bürger) no consiste en la destrucción del arte como institución, sino en la en la destrucción de la posibilidad de plantear las normas estéticas como válidas. (p.60)

En ese sentido lo que inaugura, y lo que tiene en común el minimalismo con las vanguardias transgresoras, es el hecho de poner en cuestión las normas establecidas, es decir y volviendo a Fried, poner en duda las convicciones dadas. En esa dirección, la lectura de Foster (2001) sobre el minimalismo hace hincapié en escudriñar "las reglas discursivas y las regulaciones institucionales" (p.61). De ese modo, Foster (2001) sentencia que tan sólo desde la oposición al formalismo, y desde el retorno de la vanguardia se puede llegar a entender lo que significó el minimalismo, así como, el posterior desarrollo del arte. También señala el papel del capitalismo avanzado y del proceso de la cultura de masas como elementos a tener muy en cuenta en la década de los años 1960.

Haciendo converger en nuestro foco de interés el relato de Foster (2001), sobre si el minimalismo tuvo que ver más con la puesta en duda de las reglas que regulaban el sistema de valores de las fuerzas dominantes [principalmente del formalismo], diríamos que el trabajo de Decrauzat se nos presenta hoy como un déjà $v u$, paradójicamente inverso, porque nos muestra el minimalismo, el 
op art y la abstracción pospictórica ahora como disciplinas institucionalizadas, validadas, que el artista pone bajo sospecha a partir de la transgresión de los propios límites constituyentes que las enquistaron históricamente como saber artístico.

\section{Referencias}

Fried, M. (1967). Michael Fried. Arte y objetualidad (1967) Pres. de Carolina Benavente Morales. (Carolina Benavente, Macarena Brevis, Carolina Cárdenas, trad.). Escáner cultural No147. (2012). (Obra original publicada en 1967). [en línea]. [fecha de consulta: 15 septiembre 2014]. Recuperado de http://revista.escaner.cl/node/6187 Foster, H. (2001). El retorno de lo real. la vanguardia a finales de siglo. Madrid: Ed. Akal.

Galería Parra Romero. (2013, 1 de Febrero). Conversación entre Philippe Decrauzat y Guillermo Romero Parra. [en línea]. [fecha de consulta: 13 mayo 2013]. Recuperado de http://www.parraromero.com/exposiciones/ philippe_2013/philippe.html

Guasch, A.M. (1997). El arte del siglo XX en sus exposiciones. 1945-1995. Barcelona: Ed. Serbal.

Johnson, T; Jedrzejewski, F. (2013). Looking at Numbers. Heidelberg, Springer, Dordrecht, New York, Basel, London: Ed. Springer Science \& Business Media.

Martínez, A. (2001). Arte y arquitectura del siglo XX, Volumen 2. Barcelona: Ed. Montesinos.

MoMa Museum of Modern Art. Inventing Abstraction, 1910-1925 [en línea]. [fecha de consulta: 10 noviembre 2014]. Recuperado de http:// www.moma.org/visit/calendar/exhibitions/1291

Peñaranda, L. (2010). Donald Judd ilusionista [Tesis doctoral no publicada]. Barcelona. Escuela Técnica superior de arquitectura. Universitat Politècnica de Catalunya. Recuperado de http://hdl.handle. net/10803/31862

Reichardt, J. (1966). Op Art. En N. Stangos (Ed.), Conceptos del arte moderno. Del fauvismo al posmodernismo (pp. 237-241). Barcelona: Ed: Destino.

Ruschmann, B.F. (2003). Arte geométrico: Análisis y tendencias de su 
desarrollo plástico. [Tesis doctoral no publicada]. Universidad de

Granada. Facultad de Bellas Artes. Departamento de Dibujo. Dr. Manuel Vélez Céa.

Zagrodzki, J. (s.f). New description of the world: Wacław

Szpakowski. 2b WT 017/018. [en línea]. [fecha de consulta:

1 octubre 2014]. Recuperado de http://www.2b.art.pl/index.

php?LANG=en\&struct $=9$ _19\&art_ID $=252$

Ricardo Trigo: Doctorando en Estudis Avançats en Produccions Artístiques. Universidad de Barcelona.

Contact Address: Facultad de Bellas Artes. Universidad de Barcelona. c/ Pau Gargallo 4, 08028 Barcelona (España).

E-mail address: ricardotrigomail@gmail.com 